\section{International Scientific Journal Theoretical \& Applied Science}

Asliddin Tursunovich Kuldoshev

Senior researcher

The Samarqand State Architectural-Construct Institute

Samarqand, Uzbekistan

asli-0708@mail.ru

Year: $2015 \quad$ Issue: 12 Volume: 32

Published: $30.12 .2015 \quad$ http://T-Science.org

SECTION 30. Philosophy.

\title{
THE STATE REGULATION OF ENVIRONMENTAL POLICY AND THE ECONOMY
}

\author{
Abstract: This article discusses some aspects of the methods and tools of state regulation of environmental \\ policy and its interaction with the economy. \\ Key words: ecology, environmental policy, government regulation, regulatory tools, the economy, market. \\ Language: Russian \\ Citation: Kuldoshev AT (2015) THE STATE REGULATION OF ENVIRONMENTAL POLICY AND THE \\ ECONOMY. ISJ Theoretical \& Applied Science 12 (32): 44-47. \\ Soi: http://s-o-i.org/1.1/TAS-12-32-8 Doi: crossef http://dx.doi.org/10.15863/TAS.2015.12.32.8

\section{ГОСУДАРСТВЕННОЕ РЕГУЛИРОВАНИЕ ЭКОЛОГИЧЕСКОЙ ПОЛИТИКИ И ЭКОНОМИКА}

Аннотация: В данной статье рассматриваются некоторые аспекты, методы, инструменты государственного регулирования экологической политики и её взаимодействие с экономикой.

Ключевые слова: экология, экологическая политика, государственное регулирование, инструменть регулирования, экономика, рынок.

В современном мире формирование и развитие экологической политики невозможно без экономического регулирования человеческой деятельности. В данном отношении определённую ценность представляют идеи и выводы, касающиеся взаимодействия государственного регулирования экологической политики и экономики, сделанные старшими научными сотрудниками Центра политэкономических исследований (Political Economy Research Center) в городе Боузмен (штат Монтана) Джейн C. Шоу и Ричардом Л. Строупом [3].

Очень часто экономисты полагаются на предположения, порой пренебрегая реальностью. Одна из таких реалий, которая игнорируется экономическими исследованиями последнего времени, заключается в том, что, крупные предприниматели все больше поддерживают государственное регулирование, полагая, что оно положительным образом скажется на общей продуктивности их бизнеса. Экономисты прекрасно знают, что регулирование вряд ли принесет пользу экономике, если выгоды от него не превысят издержки. Поэтому они тщательно взвешивают выгоды и издержки, связанные с теми или иными предлагаемыми мерами регулирования.

Однако в кабинетах руководителей крупных корпораций все большее распространение получает другая идея. К примеру, Тачи Киучи из Mitsubishi Electric считает, что охрана окружающей среды создает «благоприятные возможности для бизнеса» [3]. А исследователи из Аспенского института (Aspen Institute) в докладе, подготовленном с финансовой помощью целого ряда корпораций, утверждают: «Научившись “ценить экологию”, компании и финансовые институты открывают для себя новый способ приобрести конкурентные преимущества» [3].

Совершенно очевидно, что для некоторых компаний регулирование создает благоприятные деловые возможности - даже если оно влечет за собой повышение издержек. Например, компании, первыми открывшие более эффективные методы борьбы с загрязнением окружающей среды, могут получить прибыль за счет снижения издержек. Помимо этого, они выигрывают от последующей продажи этих новых технологий другим фирмам и корпорациям. Однако, некоторые специалисты по 
разработке бизнес-стратегии делают из этого перспективный вывод, заключающийся в том, что государственное регулирование ведет к инновациям, сокращающим издержки, а значит, напрямую способствует росту прибылей. Результатом этого становится снижение, как издержек, так и уровня загрязнения окружающей среды. Оценивая ситуацию с такой позиции, можно утверждать, что ужесточение государственного регулирования в области взаимодействия охраны окружающей среды и экономической политики благоприятно скажется на целом общественном механизме.

По мнению Джейн Шоу и Ричарда Строупа, главным источником идеи о том, что регулирование стимулирует инновации, а значит, повышает прибыли, являются исследования специалистов в области экономического и экологического мониторинга и бизнес-стратегии Майкла Портера и Клааса Ван дер Линде. Они представляют свои выводы в таких солидных изданиях, как Harvard Business Journal (Гарвардский деловой журнал), Scientific American (Научная Америка), и Journal of Economic Perspectives (Журнал экономических перспектив). Более того, их дебаты с экономистами на страницах Журнала экономических перспектив можно назвать единственной серьезной дискуссией по данному вопросу — и нельзя с уверенностью утверждать, что победа в этом споре досталась экономистам. Опубликовав ещё в 1995 году ряд статей, они не стали продолжать дискуссию, так как посчитали, что доводы Майкла Портера и Клааса Ван дер Линде опровергнуты. По крайней мере, так им казалось. Однако специалисты по бизнесстратегии тем временем проводили конференции, публиковали книги и убеждали журналистов (если их требовалось убеждать), что ужесточение экологического регулирования практически во всех случаях дает позитивные результаты.

В статье, опубликованной в том же 1995 году, Портер и ван дер Линде утверждали, что «правильно разработанные экологические стандарты способны стимулировать инновации, позволяющие частично, а то и с лихвой, компенсировать издержки, связанные с их соблюдением» [3]. В доказательство они привели несколько примеров:

- Ciba Geigy после введения экологических стандартов внесла в свой технологический процесс изменения, позволяющие экономить 740000 долларов в год;

- $3 \mathrm{M}$ сэкономила 120000 долларов на капитальных затратах и экономит еще по 15000 ежегодно за счет замены химических растворителей жидкостями на водяной основе;

- Robbins Company сэкономила почти 300 000 долларов на капитальных затратах и экономит еще по 115000 ежегодно за счет перехода на замкнутый цикл при гальванизации ювелирных изделий.

Здесь речь идёт о реальных случаях. Упомянутые компании действительно получают выгоду от внедрения технологий, снижающих загрязнение окружающей среды, и экономии сырья. И это естественно. Стремление повысить прибыль уже давно ведет к повышению эффективности использования материалов. Однопроцентное сокращение количества алюминия, которое идет на изготовление стандартной банки для прохладительных напитков, позволяет фирмам, специализирующимся на этой продукции, экономить до 20 млн. долларов в год. Точно также, к моменту принятия Закона о борьбе с загрязнением воздуха (Clean Air Act) уровень вредных выбросов в атмосферу снижался уже не одно десятилетие, поскольку инженеры стремились максимально увеличить эффективность сжигания топлива. Именно прибыль - главный мотив, способствующий постоянному повышению экологичности производства.

Однако Портер и ван дер Линде утверждают, что экологическое регулирование необходимо прежде всего, чтобы подстегивать инновации, которые позволят повысить прибыльность. Они утверждают, что сегодня руководству многих компаний не хватает информации и стимулов, а потому повсюду вокруг буквально «валяются десятидолларовые бумажки, которые никто не подбирает», инновационный процесс просто не идет. И именно регулирование, по их мнению, способно заставить топ-менеджеров обратить внимание на деньги, лежащие у них под ногами.

Но всё же в действительности большинство экономистов, специализирующихся на экологических проблемах, решительно отвергают идею о том, что научно-технический прогресс зависит от государственного регулирования. В ответах Карен Палмер, Уоллеса Э. Оутса и Пола Р. Портни на статью Портера и ван дер Линде на страницах Журнала экономических перспектив присутствует плохо сдерживаемое негодование. Они назвали мнение авторов о том, что экологическое регулирование следует поддерживать, невзирая на соотношение между издержками и выгодами, «довольно странным». «Традиционный подход, - объясняли экономисты, - состоит в сопоставлении позитивных результатов мер в области регулирования с расходами, необходимыми для обеспечения этих позитивных результатов» [4]. Оппоненты оценили утверждение Портера и ван дер Линде о том, что «буквально под ногами валяется множество десятидолларовых бумажек, 
которые надо просто нагнуться и подобрать», как несерьезное. Они разработали абстрактную модель, демонстрирующую, что меры экологического регулирования как правило не ведут к повышению прибыли, и объяснили, что приведенные Портером и ван дер Линде примеры относятся, по большому счёту, к числу исключений, обусловленных специфическими обстоятельствами.

Кроме того, К. Палмер, У. Оутс и П. Портни сообщили, что связались с представителями ряда фирм, в том числе и тех, что упоминали Портер и ван дер Линде. Буквально все их собеседники «однозначно заявили, что в целом экологическое регулирование приносит их компаниям значительные издержки».

Д. Шоу и Р. Строуп согласны с точкой зрения экономистов. Гипотеза о том, что регулирование пробуждает менеджеров от «спячки», заставляя их работать эффективнее, в условиях конкурентной экономики просто нелогична. Впрочем, по сути, она напоминает свою предшественницу - теорию «шокового эффекта». Согласно этой теории, популярной в свое время среди экономистов, специализирующихся на проблемах трудовых отношений, профсоюзы, добиваясь повышения зарплат, подобным «шоковым воздействием» побуждают работодателей повышать эффективность производства. Повышение зарплат, по их мнению, увеличивает производительность труда, поэтому бремя растущих издержек на жалованье работникам не перекладывается на плечи потребителей. Как выразился Нейл Чемберлен в своей работе «Труд», «удивительно, как быстро фирмы находят способы снизить издержки, как только их вынуждает к этому повышение зарплат!» [5, 289]. При наличии такого «стимула», утверждал он, «можно компенсировать дополнительные расходы на зарплату, сохранить прежний диапазон цен и получать ту же прибыль, что и раньше» [5, 289].

Но такой закономерности не существует. Исследования, проведенные в США и Великобритании, показали, что в компаниях, где действуют профсоюзы, зарплаты действительно выше, однако уровень прибылей и занятости ниже. По темпам роста «охваченные» профсоюзным движением компании и сектора также отстают от тех, где профсоюзов нет, - это еще больше дискредитирует теорию «шокового эффекта».

Теория о позитивном влиянии профсоюзных требований на экономический рост не получила особой поддержки в деловых кругах и со временем канула в Лету. Сегодня экономистам проще всего полагаться на то, что, что новая вариация на ту же тему - концепция Портера и ван дер Линде - столь же логически несостоятельна, и ее ждет такая же судьба. В условиях глобализованной экономики, роста международной торговли, расширения рынков практически во всех отраслях и бурного процесса корпоративных слияний и поглощений, фирмы, которым удается остаться на плаву, и без всякого регулирования обладают достаточной подвижностью, гибкостью и стремлением к инновациям.

Но всё же на политической арене очень часто действует принцип: «логика - аргумент неудачников». Одной логики - т.е. теории недостаточно. На взгляд Д. Шоу и Р. Строуп, экономисты должны уделить этому вопросу больше внимания и подойти к нему с опытных (эмпирических) позиций. Они должны настойчивее опровергать идею о том, что ужесточение экологического регулирования в подавляющем большинстве случаев оправдано, поскольку «шоковым» методом вынуждает фирмы внедрять передовые технологии, от чего выигрывают все. Этот вариант куда опаснее первоначальной идеи «шокового эффекта».

У крупных компаний всегда возникает соблазн добиваться ужесточения регулирования ведь для их более слабых конкурентов повышение издержек становится более тяжким бременем, чем для них самих. А сегодня они могут делать это под благовидным предлогом поддержки полезного для общества дела. Одним из возможных результатов этого может стать договоренность между крупнейшими компаниями о характере мер регулирования, которые принесли бы им самим особые преимущества. В статье, опубликованной в журнале Regulation (Регулирование), Брюс Яндл пишет, что некоторые нефтегазовые компании уже сообразили, как извлечь выгоду из Киотского протокола, посвященного борьбе с климатическими изменениями, - это можно сделать за счет других фирм [6]. Он также отметил, что меры регулирования, призванные защитить северную пятнистую сову и заключавшиеся в резком ограничении вырубки в общественных лесных угодьях, обернулись повышением цен на древесину, что выгодно компаниям вроде Weyerhaeuser, которые ведут заготовку леса в основном на собственных землях [6]. (Это позволяет объяснить, почему глава Weyerhaeuser c таким энтузиазмом поддержал указанные меры). Таким образом, государственное регулирование, независимо от его пользы для экологии, легко превращается в орудие борьбы с конкурентами.

Исходя из всего вышеизложенного, можно сделать определённые выводы. Например: государственное регулирование экологической политики не всегда приводит к оздоровлению 


\begin{tabular}{l|lrl|l|ll} 
& ISRA (India) & $=\mathbf{1 . 3 4 4}$ & SIS (USA) & $=\mathbf{0 . 9 1 2}$ & ICV (Poland) & $=\mathbf{6 . 6 3 0}$ \\
Impact Factor: & ISI (Dubai, UAE) $=\mathbf{0 . 8 2 9}$ & PUHL (Russia) $=\mathbf{0 . 1 7 9}$ & PIF (India) & $=\mathbf{1 . 9 4 0}$ \\
& GIF (Australia) & $\mathbf{0 . 5 6 4}$ & ESJI (KZ) & $=1.042$ & & \\
& JIF & $\mathbf{1 . 5 0 0}$ & SJIF (Morocco) $=\mathbf{2 . 0 3 1}$ & &
\end{tabular}

окружающей среды, снижению издержек и повышению производительности труда; некоторые производители и владельцы крупных корпораций используют регуляторы экологической деятельности с целью приобретения конкурентного преимущества и уничтожения соперника в конкурентной борьбе; государственное регулирование не должно глубоко проникать в сферу экономики, но на этом фоне необходимо создание органов надзора за законностью выполнения регулятивной политики в этих сферах, повышение эффективной деятельности антимонопольных комитетов и др.

В Республике Узбекистан экологическая политика проводится уже более 20 лет [10]. Сегодня определённое количество предприятий нашей страны выходит на мировой уровень развития и в этих условиях дальнейшее регулирование экологической политики без вмешательства в экономическое развитие имеет решающее значение для процветания государства и общества.

\section{References:}

1. (2014) Konstitucija Respubliki Uzbekistan. Tashkent, Uzbekistan, 2014.

2. Karimov IA (1997) Uzbekistan na poroge XXI veka: ugrozy bezopasnosti, uslovii i garantii progressa. Tashkent, Uzbekistan, 1997.

3. Shaw JS, Stroup RL (2015) Do Environmental Regulations Increase Economic Efficiency? // Regulation. Vol. 23. № 1.

4. (1995) Journal of Economic Perspectives. 1995, №5.

5. Chamberlain N (1958) Labor. 1958. pp. 289.

6. Yandle B (2015) The Kyoto`s Protocol... /Regulation.Vol. 22. № 3.

7. Kuljasov I (2004) Jekologicheskaja modernizacija: teorija i praktiki / Red. Ju.
Pahomov (predislovie). - Sankt-Peterburg: NIIH SPbGU, 2004. - 158 p.

8. Makkenzi RD (2000) Jekologicheskij podhod k izucheniju chelovecheskogo soobshhestva // Social'nye i gumanitarnye nauki za rubezhom. Ser. 11. Sociologija. 2000. - № 4. pp. 136-152.

9. (2015) Konferencija po izmeneniju klimata v Parizhe 2015 goda. Available: http://www.un.org/sustainabledevelopment/ru/c op21/ (Accessed: 10.12.2015).

10. (2015) Jekologicheskaja politika i bezopasnost'. Available: $\quad$ http://uznature.uz/?q=ru/node/698 (Accessed: 10.12.2015). 